1 Department of Primary Care and Public Health, Imperial College London

2 Bridgewater Surgeries, Watford

3 Cleveland Clinic London

Correspondence to: A Majeed a.majeed@imperial.ac.uk, Twitter @Azeem_Majeed; S Hodes simon.hodes@nhs.net Cite this as: BMJ 2022;376:0406 http://dx.doi.org/10.1136/bmj.0406 Published: 02 March 2022

\title{
Has the covid pandemic changed the debate about nationalising GPs?
}

\author{
The pandemic has led the UK health secretary into a debate on whether GPs should be directly \\ employed by the NHS. Azeem Majeed argues that this is an opportunity to correct a flawed model, \\ but Simon Hodes says that partnerships are still the best model for primary care
}

Azeem Majeed, ${ }^{1}$ Simon Hodes ${ }^{2,3}$

\section{Yes-Azeem Majeed}

The intense micromanagement of general practices by NHS England since the start of the covid-19 pandemic has shattered the illusion that NHS GPs are truly "independent."

For example, during the pandemic NHS practices have often received weekly updates from NHS England on how they should provide primary care services. ${ }^{1}$ The opening hours and working arrangements of general practices are also highly regulated by NHS England. And GPs are not independent contractors in a way that professionals working in other fields, or indeed primary care physicians working overseas, would recognise.

GPs are not even able to offer private medical services to their patients in the same way as NHS trusts or dentists. In effect, they have all of the disadvantages of being self-employed contractors and none of the benefits of being NHS employees.

\section{A decade of underinvestment}

For more than a decade, primary care in England has suffered from underinvestment and a lack of key staff such as GPs and practice nurses. In contrast, the NHS hospital sector, although not without its own problems, has seen its funding and medical staffing increase at a much quicker rate than NHS primary care. ${ }^{2}$ But more NHS work continues to be shifted to primary care without being followed by a commensurate increase in funding and staffing. Attempts by NHS England to prevent this, such as introducing the NHS hospital contract, have failed. ${ }^{3}$

Clearly, NHS England is not going to invest adequately in the current independent contractor model of general practice, so being a GP partner is increasingly unattractive for younger GPs. ${ }^{4}$ It's therefore time to look seriously at the alternative-GPs becoming salaried employees of the NHS.

Of course, being employed by the NHS is not a panacea. Many NHS staff employed by NHS trusts suffer from stress and overwork, just like those working in primary care. But they're not personally responsible for the ownership of their employing organisations, and their income doesn't depend on how well their organisation performs financially. Their working hours are also better regulated than those of self-employed GPs.

If GPs had employment contracts similar to those of NHS consultants, they could then have job plans with time allocated for activities such as quality improvement, NHS management, teaching, training, and research. Currently, these activities are often done on top of their regular working hours. Working in organisations that employ large numbers of GPs would also create opportunities for a better career structure. For example, it may be possible to create posts for GPs who specialise in areas such as the care of elderly people or child health, as well as for GPs who take on clinical leadership, quality improvement, and NHS management roles in addition to a clinical role. ${ }^{5}$

Finally, GPs becoming NHS employees would make NHS England directly responsible for delivery of primary care services, just as it already is for specialist services. And it would be the responsibility of NHS England-not GPs-to ensure that patients had timely access to a comprehensive range of high quality primary care services and the infrastructure needed to deliver this care.

An increasing proportion of NHS GPs are already salaried, so the future for GPs looks to be heading in this direction. The question for GPs is: do they want to be employed by the NHS with similar terms of employment to consultants, or do they want to be employed by private companies and

"mega-partnerships," with the inevitable variability in terms of the employment they will offer?

\section{No-Simon Hodes}

Since the NHS was founded in 1948, GP partners have been classed as self-employed practitioners. ${ }^{6}$ To this day, GP partnerships function as small to medium sized businesses contracted by NHS commissioners to provide care in a geographical or population area. Although England's health secretary, Sajid Javid, recently mooted "nationalising" general practice, ${ }^{7}$ that same week the BMA announced plans for a "new deal" for general practice based on the independent model.

Each general practice can organise itself to provide services to the NHS in the most efficient and flexible way possible in its local area. Partnerships offer accountability, responsibility, and exceptional value for money. This has been highlighted during the pandemic, as GPs have responded rapidly at a local level to help protect their communities. GPs remain at the heart of health promotion and prevention strategies, tackling health inequalities and providing mass vaccination-all key determinants of health. All of this for around $£_{3}$ per week per patient, paid to the practice. ${ }^{8}$ 
In recent years, policy has pushed England's general practices into "primary care networks" serving 30 000-50 000 patients, with a clinical director at the helm-potentially reducing the need for so many partners in the constituent practices. ${ }^{9}$ Large group general practices (or "super practices") are run by small numbers of managing partners or by private companies. There has been much disquiet about US companies buying up chains of NHS general practices. $^{10}$

Continuity of care is best provided by stable GP teams, which are traditionally led by partnerships. Continuity has a strong evidence base for reduced morbidity and mortality, ${ }^{11}$ improved patient satisfaction, reduced referrals, safer prescribing, and lower admission rates. It also leads to improved efficiency, as well as higher satisfaction for patients and healthcare professionals.

\section{Changing landscapes}

Although the majority of GPs remain as partners, it's true that the percentage is falling. Over the past 20 years we've seen a major shift away from newly qualified GPs seeking lifelong partnerships, to a generation of GPs seeking salaried, locum, or portfolio work. There are many reasons for this, including concerns about uncapped hours and responsibility, building liabilities, and a narrowing gap in earnings between partners and non-partners. Historically, an income was attracted for each partner to each practice, but this was scrapped under contract changes, and many would argue that it triggered the demise of partnerships as we know them.

GP teams are working ever harder-expanding in size and workforce, with increasing reliance on allied healthcare professionals, any of whom could potentially become partners-to support a dwindling workforce while caring for an ageing, growing population living for longer with more complex health needs and long term conditions. GPs remain the ultimate generalist specialists, ${ }^{12}$ and perhaps this needs to be recognised in consultant status. ${ }^{13}$ And while the number of GPs is falling, the number of patients per GP in the UK is rising rapidly. ${ }^{14}$

The government's 2019 GP Partnership Review ${ }^{15}$ concluded, "We need a clear vision for the future and the role that general practice and partnerships will play in that." The NHS Confederation commented that "our members report support for the current model in terms of its basis in serving local populations of registered patients which facilitates continuity of care." ${ }^{16}$ GP teams deal with around $90 \%$ of all NHS patient contacts-for less than $10 \%$ of the overall NHS budget. As the NHS Five Year Forward View says, "If general practice fails, the NHS fails." 17

It's understandable that a new generation of GPs don't relish the responsibility, workload, and financial commitment required in owning and running a practice, including estate planning and organising staffing. But ultimately, the autonomy this brings and the ability to plan your own destiny, prepare your working environment, and shape your workforce and strategy is what attracts many GPs to partnership and continues to provide so much longlasting job satisfaction.

Policy makers cannot sleepwalk into the GP crisis any longer, and they must invest in the best model of care delivery. For now, that is almost certainly still best provided through an updated independent partnership model.
Provenance and peer review: Commissioned, not peer reviewed.

Majeed A, Maile EJ, Bindman AB. The primary care response to COVID-19 in England's National Health Service. J R Soc Med2020;113:208-10. doi: 10.1177/0141076820931452 pmid: 32521196

2 Anderson M, O'Neill C, Macleod Clark J, etal. Securing a sustainable and fit-for-purpose UK health and care workforce. Lancet 2021;397:1992-2011.

doi: 10.1016/S0140-6736(21)00231-2 pmid: 33965066

3 Price A, Majeed A. Improving how secondary care and general practice in England work together: requirements in the NHS Standard Contract. J R Soc Med 2018;111:42-6. doi: 10.1177/0141076817738504 pmid: 29035668

4 Rimmer A. GPs move towards industrial action after rejecting "rescue plan" for general practice. BMJ 2021;375:n2594. doi: 10.1136/bmj.n2594 pmid: 34686485

5 Majeed A, Buckman L. Should all GPs become NHS employees?BMJ 2016;355:15064. doi: 10.1136/bmj.i5064 pmid: 27707698

6 Beech J, Baird B. GP funding and contracts explained. King's Fund. 11 Jun 2020. https://www.kingsfund.org.uk/publications/gp-funding-and-contracts-explained

7 lacobucci G. Government wants more GPs to be employed by hospital trusts, says news report. BMJ 2022;376:0267. doi: 10.1136/bmj.0267 pmid: 35105665

$8 \quad$ NHS Digital. NHS payments to general practice England, 2020/21. 25 Nov 2021. https://digital.nhs.uk/data-and-information/publications/statistical/nhs-payments-to-general-practice/england2020-21

9 O'Dowd A. Primary care networks: more effort is needed to engage with general practices, says report. (Rapid response) BM/2020;371:m4551. https://www.bmi.com/content/371/bmi.m4551/r . doi: 10.1136/bmj.m4551 pmid: 33218976

10 lacobucci G. Subsidiary of US healthcare firm will run more than $50 \mathrm{GP}$ practices after takeover deal. BMJ 2021;372:n519. doi: 10.1136/bmj.n519 pmid: 33619035

11 Baker R, Freeman GK, Haggerty J, Bankart MJ, Nockels KH. Primary medical care continuity and patient mortality: a systematic review. Br J Gen Pract 2020;70:e600-11. doi: 10.3399/bjgp20X712289. https://bjgp.org/content/early/2020/08/10/bigp20X712289. pmid: 32784220

12 McCarthy M. Mary McCarthy: The value of generalists. BMJ Opinion 2021 Aug 27. https://blogs.bmj.com/bmj/2021/08/27/mary-mccarthy-the-value-of-generalists/

13 Royal College of General Practitioners, General Medical Council, BMA. General Practitioners: Specialists in general practice-joint statement. Sep 2019. https://www.rcgp.org.uk/policy/rcgppolicy-areas/gps-as-specialists.aspx

14 BMA. Pressures in general practice data analysis. https://www.bma.org.uk/advice-and-support/nhsdelivery-and-workforce/pressures/pressures-in-general-practice

15 Department of Health and Social Care. GP partnership review: final report. 15 Jan 2019 https://assets.publishing.service.gov.uk/government/uploads/system/uploads/attachment_data/file/770916/gp-partnership-review-final-report.pdf

16 NHS Confederation. GP partnership review: NHS Clinical Commissioners' response. 6 Sep 2018 https://www.nhsconfed.org/publications/gp-partnership-review

17 Hodes S, Hussain S, Jha N, Toberty L, Welch E. If general practice fails, the NHS fails. BMJ Opinion 2021 May 14. https://blogs.bmj.com/bmi/2021/05/14/if-general-practice-fails-the-nhs-fails/ 